\title{
Mutation of megalin leads to urinary loss of selenoprotein $P$ and selenium deficiency in serum, liver, kidneys and brain
}

Jazmin Chiu-Ugalde ${ }^{1}$, Franziska Theilig ${ }^{2}$, Thomas Behrends ${ }^{1}$, Julia Drebes ${ }^{1}$, Carolin Sieland ${ }^{1}$, Prema Subbarayal ${ }^{1}$, Josef Köhrle $^{1}$, Annette Hammes ${ }^{3}$, Lutz Schomburg ${ }^{1 *}$, Ulrich Schweizer ${ }^{1 *}$

${ }^{1}$ Institut für Experimentelle Endokrinologie und EnForCé,

${ }^{2}$ Zentrum für Anatomie, Vegetative Anatomie,

Charité-Universitätsmedizin Berlin,

${ }^{3}$ Max Delbrück Centrum, Berlin, Germany

Running head: Urinary Loss of SePP in megalin-deficient mice

*address correspondence to:

Dr. Ulrich Schweizer or Prof. Dr. Lutz Schomburg

Charité-Universitätsmedizin Berlin

Institut für Experimentelle Endokrinologie

Augustenburger Platz 1

13353 Berlin, Germany.

Tel ++4930450524080

Fax ++4930450524922

E-Mail: ulrich.schweizer@.charite.de; lutz.schomburg@charite.de 


\section{Synopsis:}

Distribution of selenium (Se) within the mammalian body is mediated by selenoprotein $\mathrm{P}$ (SePP), a Se-rich glycoprotein secreted by hepatocytes. Genetic and biochemical evidence indicate that the endocytic receptors ApoER2 and megalin mediate tissue-specific SePP uptake. Megalin-mutant mice were fed diets containing adequate $(0.15 \mathrm{ppm})$ or low $(0.08 \mathrm{ppm})$ Se content and were analyzed for tissue and plasma Se levels, cellular glutathione peroxidase (GPx) activities, and protein expression patterns. Megalin-mutant mice display increased urinary Se loss, which correlates with SePP excretion in their urine. Accordingly, serum Se and SePP are significantly reduced in megalin-mutant mice reaching marginal levels on the low Se diet. Moreover, kidney Se content and expression of renal selenoproteins are accordingly reduced as is SePP internalization along the proximal tubule epithelium. While GPx4 expression is not altered in testis, Se and GPx activity in liver and brain were significantly reduced. When fed a low Se diet, megalinmutant mice develop impaired movement coordination, but no astrogliosis. Our findings suggest that megalin prevents urinary SePP loss and participates in brain Se/SePP uptake. 


\section{Introduction}

The trace element selenium (Se) ${ }^{1}$ is essential for mammals. It is required for synthesis and function of selenoproteins, i.e. proteins containing the rare amino acid, selenocysteine (Sec). Representing the $21^{\text {st }}$ proteinogenic amino acid, Sec is incorporated into proteins in response to UGA codons which are recoded by the action of a cisacting selenocysteine insertion sequence located in the 3'-untranslated region of the mRNA [10]. The human and rodent genomes contain 25 and 24 genes encoding selenoproteins, respectively [15]. Targeted disruption of genes encoding individual selenoproteins or selenocysteine tRNA has provided ample evidence for specific functions of selenoproteins in cellular proliferation, differentiation, and survival, as well as roles in thyroid hormone metabolism, heart function, cancer progression, and neurobiology [7].

In humans, low plasma Se levels have been associated with increased risk of cancer, cardiovascular and autoimmune disease [24]. The majority of plasma Se is contained in selenoprotein P (SePP), the key Se transport protein in mammals [4]. Targeted genetic inactivation of the Sepp gene leads to a complex phenotype in mice, including male infertility and neurological impairments [12;30]. Plasma SePP is mainly produced in hepatocytes and participates in Se uptake into kidney, testis and brain. This was shown by reduced Se levels in tissues of mice incapable of hepatic selenoprotein biosynthesis and in $S e p p^{-/-}$mice genetically complemented with a hepatocyte-specific SEPP1 transgene [26;32]. Recently, lipoprotein receptor-related protein 8 (Lrp8, ApoER2) has been identified as a receptor mediating SePP uptake in testis [1;23] and brain [5]. Lipoprotein receptor-related proteins represent a large family of endocytic receptors, with broad and often overlapping substrate specificities [11;21]. Since ApoER2 is not expressed in the SePP target organ kidney, it was postulated that ApoER2 is not the only SePP receptor. Megalin (LRP2) is structurally related to ApoER2 and is highly expressed in the kidney where it is involved in re-uptake of many plasma proteins along the proximal tubulus. Megalin-null mice have been generated, but rarely survive birth [42]. Thus, Olson and collaborators elegantly demonstrated megalin-dependent SePP binding to embryonic kidney [22], but were not able to assess the role of megalin in Se homeostasis in adult animals. We took advantage of a megalin-mutant mouse strain carrying a missense mutation in the extracellular domain of megalin, line 267 [44]. Of this strain, a moderate fraction of $\operatorname{Lrp} 2^{267 / 267}$ mice survive into adulthood. We investigated Se content and selenoprotein expression in different organs of adult $\operatorname{Lrp} 2^{267 / 267}$ mice and assessed the importance of Se supply by feeding diets containing adequate or low Se levels. We found SePP excreted in the urine of $\operatorname{Lrp}^{267 / 267}$ mice, but not of wild-type littermates. Accordingly, plasma Se levels were significantly decreased in megalin mutants as was expression of the Se-marker enzyme, glutathione peroxidase 1 in kidney and brain. Upon dietary Se restriction for four weeks, movement coordination deteriorated in $\operatorname{Lrp}^{267 / 267}$, but not in wild-type, mice. In summary, our data suggest that megalin represents a physiological SePP receptor in kidney mediating the re-uptake of secreted SePP from the primary urine, and a SePP receptor in brain participating in Se uptake at the blood-brain-or blood-cerebrospinal fluid-barrier.

\section{Materials and Methods}

\section{Animals}

A mouse strain (line 267) carrying a nonsense mutation at tyrosine 2721 in the extracellular domain of megalin was maintained on a mixed FVB/N C57B1/6J genetic background [44]. In order to distinguish this mutant allele from the engineered $\operatorname{Lrp} 2^{\text {null }}$ allele, we designated the mutant allele in this manuscript as $L r p 2^{267}$ and the wild-type allele as $\operatorname{Lrp}^{+}{ }^{+}$. The breeding colony was maintained on breeding diets (Ssniff) containing on average 0.2-0.3 ppm Se. In order to modify the Se status of the experimental groups, weanling mice were assigned to a low Se diet (Altromin, Lage, Germany, diet C1045 containing $0.08 \mathrm{ppm} \mathrm{Se}$ ) or the same diet supplemented with selenite to an adequate Se concentration $(0.15 \mathrm{ppm}$ Se, recommended dietary allowance, RDA). Se content of the diets used in the experiments was determined by total reflection X-ray fluorescence (TXRF) analysis and verified the intended Se content, i.e., 0.08 ppm Se (Low Se) and $0.15 \mathrm{ppm} \mathrm{Se}$ (RDA Se), respectively. Because of the low rate of survival into adulthood of $\operatorname{Lrp}^{267 / 267}$ mice, animals from both sexes were analyzed and pooled, except when sexually dimorphic parameters were measured [27]. Animal experiments were approved by the local governmental authorities (Landesamtes für Gesundheit und Soziales, LAGeSo Berlin, Germany). Genotyping was done by PCR using primers fwd: GTAACTGGAAGGCATCTTCTC and rev: CTCATCTGAGGTGTCATTGTC (294 bp). Subsequent restriction with Msel resulted in fragments of $55 \mathrm{bp}$ and $239 \mathrm{bp}$ from the mutant $\left(\operatorname{Lrp} 2^{267}\right)$ allele.

Cell culture and binding assays 
Rat yolk sac epithelial BN16 cells were maintained in Iscove's Basal medium with 10\% FCS. HepG2 cells were grown to confluency in DMEM:F12 containing 10\% FCS. After medium exchange to serum-free conditions and addition of $50 \mathrm{nM}{ }^{75} \mathrm{Se}$-selenite (Hartmann Analytik, Braunschweig, Germany) per $75 \mathrm{~cm}^{2}$ flask, cells were incubated for three more days. Then, cell culture supernatants containing ${ }^{75}$ Se-labelled SePP were collected and concentrated using Amicon concentrators (cut-off MW 30,000). The ${ }^{75}$ Se-labelled supernatant was added as a tracer to human serum (f.c. $3 \mu \mathrm{g} \mathrm{SePP} / \mathrm{ml})$. For binding assays, 200,000 BN16 cells/well were incubated in 24 well plates with $500 \mu 1$ Isove's medium without FCS at $4^{\circ} \mathrm{C}$. Increasing amounts of labelled serum were combined with Iscove's medium in a total volume of $500 \mu \mathrm{l}$ in duplicate wells. After 4 hours at $4^{\circ} \mathrm{C}$, the supernatant was removed and cells were lyzed with $0.1 \mathrm{M}$ $\mathrm{NaOH}$. The lysate was counted in a $\gamma$-counter (Wizard, Perkin Elmer, Rodgau, Germany). Recombinant soluble GSTRAP (receptor associated protein $[0.1 \mathrm{mg} / \mathrm{ml}$ in Iscove's medium]) was used as a specific LRP-inhibitor and preincubated with cells for 2 hours. Then, cells were incubated for 4 hours at $4^{\circ} \mathrm{C}$ with ${ }^{75} \mathrm{Se}-\mathrm{SePP} / \mathrm{serum}(1.4 \mathrm{mg} / \mathrm{ml}$ corresponding to $50 \%$ binding) in the presence of GST-RAP.

Enzyme assays

GPx activity was determined in tissue homogenates and serum as described [30]. In brief, NADPH consumption by glutathione reductase was monitored at $340 \mathrm{~nm}$ as a measure of the GSSG formation catalysed by GPx. Enzymatic activity was recorded at $37^{\circ} \mathrm{C}$ in a buffer containing $0.02 \mathrm{M}$ potassium phosphate, $\mathrm{pH}$ 7.0, $0.6 \mathrm{mM}$ EDTA, $0.15 \mathrm{mM}$ NADPH, $2 \mathrm{mM} \mathrm{GSH}$ and 4 units of glutathione reductase (Calbiochem, Merck, Darmstadt, Germany). The reaction was started by addition of $0.1 \mathrm{mM}$ tert-butylhydroperoxide as substrate. Background NADPH consumption was determined in the presence of $100 \mathrm{mM}$ mercaptosuccinate and subtracted. Protein concentration was determined by the method of Bradford using IgG as a standard.

\section{Selenium measurements}

Se was determined using TXRF using a Picofox ${ }^{\mathrm{TM}} \mathrm{S} 2$ instrument (Bruker, Karlsruhe, Germany) [37]. Gallium was used as internal standard for quantification and reference samples for urine and serum (Sero, Billingstad, Norway) were used and always within the reference range. For tissue Se content, protein extracts were oxidatively digested in $0.1 \mathrm{M}$ ultrapure nitric acid for 3 hours at $150^{\circ} \mathrm{C}$ before TXRF analysis.

Western blot

For GPx1 (rabbit antiserum from Abcam, Cambridge, UK), $40 \mu \mathrm{g}$ (kidney, liver) or $100 \mu \mathrm{g}$ (brain) protein from cytosolic fraction was separated in SDS/12\% polyacrylamide gels. For GPx4 (rabbit antiserum from Abcam) from testis, $50 \mu \mathrm{g}$ of whole homogenate was used. An antiserum directed towards SePP had been generated earlier in rabbits by immunization with a synthetic peptide (ImmunoGlobe, Himmelstadt, Germany), and its specificity has been verified using wild-type and Sepp-knockout mice as described earlier [31]. For SePP quantification, $0.5 \mu 1$ serum and $10 \mu 1$ urine were applied per lane. Deglycosylation was achieved by incubation with N-glycosylase F (Roche, Mannheim, Germany). After electrotransfer, PVDF membranes were stained with Ponceau Red, photographed and blocked with $5 \%$ BSA for 1 hour at $25^{\circ} \mathrm{C}$. Polyclonal antibodies were used at 1:2000 dilution. Rabbit polyclonal $\beta$-actin antiserum (Sigma, Munich, Germay) was used at 1:3000 dilution.

\section{Immunohistochemistry}

The guinea pig anti-megalin antibody was made in our laboratory [9]. Paraffin sections were blocked with 5\% skim milk/PBS, incubated with the respective primary antibody followed by incubation with suitable Cy-2, Cy-3-coupled secondary antibodies (Dianova, Hamburg, Germany). In double-labelling techniques the different primary antibodies were administered consecutively. Sections were analyzed using a multilaser confocal scanning microscope (LSM5 exciter, Carl Zeiss, Jena, Germany).

\section{Rotarod}

Rotarod analysis was carried out as described [32]. Animals were placed on the rotating drum at 4 rounds per min (rpm). After 2 min of accommodation, the rotation was linearly accelerated over 3 min to $40 \mathrm{rpm}$. The retention time spent on top of the rotating drum was recorded.

Statistics

For all computations, GraphPad Prism software was used for the tests indicated in the figure legends. Results are presented as means \pm standard error of the mean (S.E.M.).

\section{Results}

RAP-sensitive binding of ${ }^{75} \mathrm{Se}$-SePP to BN16 cells 
In order to test the direct interaction of SePP with megalin in living cells, we incubated BN16 cells with ${ }^{75} \mathrm{Se}-\mathrm{SePP}$. BN16 cells were chosen as an established model system for megalin substrate binding [9, 34], because megalin is the only lipoprotein receptor-related protein expressed in these cells [9]. Radioactive SePP was produced and secreted by HepG2 human hepatoma cells metabolically labelled with ${ }^{75}$ Se-selenite (Fig. 1A). SePP was the only ${ }^{75}$ Se-labelled protein detected in HepG2 culture supernatant. Tracer amounts of ${ }^{75} \mathrm{Se}-\mathrm{SePP}$ were added to human serum and the binding of SePP to BN16 cells was assessed in the presence of other serum proteins that may compete with SePP for megalin binding (Fig. 1B). Pre-incubation with the specific LRP antagonist, receptor-associated protein (RAP), significantly diminished ${ }^{75} \mathrm{Se}-\mathrm{SePP}$ binding to BN16 cells, supporting the specificity of the interaction (Fig. 1C).

\section{Urinary loss of SePP and selenium in megalin-mutant mice}

Proteinuria is one hallmark phenotype of LRP2-deficient patients (OMIM 222448; [14]) and Lrp $2^{\text {null }}$ mice [42] and reflects the failure of renal re-uptake of certain filtrated plasma proteins. Megalin-mutant mice of line $267\left(\operatorname{Lrp} 2^{267}\right.$ ) carry a stop mutation in the extracellular domain of megalin, which is predicted to abrogate megalin ${ }^{\mathrm{Y} 2721 \mathrm{X}}$ function as an endocytic receptor (Fig. 2A). Proteinuria was also found in $\operatorname{Lrp} 2^{267 / 267}$ mice (Fig. 2B). Similarly, urinary Se content was increased in the mutants (Fig. 2C). Therefore, we speculated that SePP could be among the plasma proteins excreted in $\operatorname{Lrp}^{267 / 267}$ mice, if the potential interaction of SePP and megalin in the renal proximal tubulus is of physiological significance. Immunoblotting revealed that SePP is present in the urine of $\operatorname{Lrp} 2^{267 / 267}$, but not wild-type, mice (Fig.2D). SePP migrated at several mobilities (full-length fully glycosylated SePP at 55kDa and smaller species around $45 \mathrm{kDa}$ ) were detected in the urine of mutant mice and both co-migrated with the respective isoforms in serum (Fig. 2E). The smaller species likely represent proteolytic fragments of SePP, since removal of N-linked glycosides shifted all species similarly [17]. The size difference is compatible with limited proteolysis of SePP by peptidases of the kallikrein family as suggested by Saito et al. [28]. Interestingly, the small fragment is more abundant in serum from Se-adequate mice. Immunohistochemistry demonstrated immunoreactivity for SePP along the kidney proximal tubulus epithelium (Fig. 2F). Accordingly, the SePP-immunoreactive, bona-fide endocytic, structures were most abundant along the S1 segment of wild-type mice, but were not observed in $L r p 2^{267 / 267}$ mice, indicating that they might represent endocytic SePP-containing vesicles (Fig. 2F, G). In contrast to an earlier report (16), we did not observe co-localization of SePP and megalin, possibly due to our antibody binding an epitope overlapping with the megalin interaction site.

\section{Reduced serum selenium and plasma glutathione peroxidase activity in Lrp $2^{267 / 267}$ mice}

In a first attempt to test whether urinary excretion of SePP alters Se metabolism, we determined serum Se levels in $\operatorname{Lrp} 2^{267 / 267}$ mice and compared them with wild type littermates. Serum Se is reduced in $\operatorname{Lrp} 2^{267 / 267}$ mice irrespective of food Se content (Fig. 3A). Similarly, we quantified serum SePP concentrations by immunoblotting and densitometry. Levels of SePP were reduced in $\operatorname{Lrp}^{267 / 267}$ mice and correlated with Se concentrations, supporting the notion that serum Se is mainly determined by serum SePP (Fig. 3B). Activity of plasma glutathione peroxidase (GPx) was likewise reduced in megalin-mutant (Fig. 3C). The profound reduction of serum Se and SePP concentration indicates that urinary loss of SePP represents a physiologically relevant pathway affecting whole body Se status and regular Se transport and distribution. Since plasma GPx is secreted by proximal tubule cells, decreased plasma GPx levels suggested renal Se deficiency in megalin-1mutant mice.

\section{Kidney selenoprotein expression is reduced in megalin-mutant mice}

Since the kidney is apparently re-absorbing significant amounts of Se in the form of SePP from the primary filtrate, we investigated to which degree the kidney depends on this process for selenoprotein expression. At adequate dietary Se intake (RDA diet), renal Se content was not sigificantly changed in $\operatorname{Lrp}^{267 / 267}$ mice. However, upon dietary Se restriction, renal Se content was significantly reduced in the mutants (table 1). Expression of the selenoenzyme GPx1 represents a sensitive biomarker for cellular Se status and might be more indicative of Se status than total tissue concentration of Se. Therefore, we investigated GPx1 expression in the kidney in relation to megalin genotype. While immunoblotting for GPX1 in cytosolic homogenates was less sensitive (Fig. 4A), enzymatic activity measurements revealed significantly reduced GPx activities in $\operatorname{Lrp} 2^{267 / 267}$ mice. This effect was further exacerbated by dietary Se restriction (Fig. 4B). Immunohistochemical staining for GPx1 appeared stronger in S1 segments compared to more distal tubule epithelium (Fig. 4C, D). Interestingly, this difference was abolished in $\operatorname{Lrp} 2^{267 / 267}$ mice, and may thus be derived from the higher rate of SePP-internalization along the initial segment. 
Sepp mRNA is highly expressed in the kidney, but its role there remained unclear [32]. When we performed immunoblot experiments with our new SePP antibody, we found several SePP-immunoreactive bands in kidney lysate (Fig. 4E). These bands were not detectable in Sepp ${ }^{--}$kidney lysate. Moreover, the size distribution of the renal SePP isoforms was different from that in serum. In particular, the most prominent band exhibits a mobility compatible with $38 \mathrm{kDa}$, the molecular mass corresponding to full-length, non-glycosylated SePP. The presence of this band likely indicates local SePP biosynthesis (Fig. 4E). The fully glycosyated bands present in serum are also detected. We cannot distinguish at present whether these derive from de-novo synthesized SePP or from endocytosed SePP, or both. The minor species may represent incompletely glycosylated SePP, a finding corroborated by N-glycosylase treatment (not shown). Renal SePP biosynthesis was diminished by dietary Se deficiency and in kidneys of $\operatorname{Lrp} 2^{267 / 267}$ mice (Fig. 4F). Together our results indicate that Se required for selenoprotein synthesis in renal tubule cells is accumulated to a significant extent through megalin-dependent SePP uptake at the apical membrane of the proximal tubules.

\section{Selenoprotein expression in liver and testis}

Our results of diminished serum Se levels in $\operatorname{Lrp}^{267 / 267}$ mice raised the question whether the mutants are generally depleted of Se. The liver plays a central role in Se metabolism and is sensitive to dietary Se status. Accordingly, liver Se content is significantly lower in animals fed low Se diet as compared to RDA diet (table 1). Similar as in kidney, hepatic GPx1 protein expression is a less sensitive Se marker than enzymatic activity of GPx1 (Fig. 5A, B) and is influenced by both dietary Se intake and megalin-genotype (Fig. 5B). Contrary to this reduction in GPx1 activity, serum SePP is not significantly reduced (Fig 3B). When fed RDA diet, the liver of $L r p 2^{267 / 267}$ mice does not exhaust its Se stores, despite increased urinary SePP loss. Therefore, the question arises whether other known SePP target tissues become Se-deficient in $\operatorname{Lrp} 2^{267 / 267}$ mutants. Testis is a hierarchically well-supplied Se target organ depending on SePP and ApoER2/Lrp 8 for SePP uptake and Se status [22]. GPx4 expression can be used as a surrogate marker for testis Se content and sperm quality [1;26]. Clearly, testicular GPx4 expression is preserved in $L r p 2^{267 / 267}$ mice above the level in $\mathrm{Lrp}^{-/-}$mice (Fig. 5B). This finding supports the role for circulating SePP in testicular Se uptake, but rules out a direct contribution of megalin in this process.

Brain Se status Lrp $2^{267 / 267}$ mice

The brain represents another well-supplied tissue with regard to Se, since even prolonged dietary Se deficiency does not lead to neurological symptoms. The current model suggests that SePP is the main Se carrier into and within brain. Mice deficient for ApoER2 suffer from neurodegeneration and have low Se content in the brain when fed a low Se diet [5]. However, ApoER2 is mainly expressed in neurons [3]. Thus, we speculated that a second bona-fide SePP receptor may exist at the blood-brain- and/or blood-cerebrospinal fluid-barrier. Megalin is known to be expressed in the choroid plexus and along the ependymal lining of the ventricles [45]. Therefore, we tested whether brain Se content and selenoprotein expression is reduced in $\operatorname{Lrp} 2^{267 / 267}$ mice. While brain Se content was not significantly diminished in megalin-mutant mice (table 1), brain GPx activity was more sensitive to megalin-mutation (Fig. 6A). Despite the mild exencephaly of megalin-mutant mice, their performance at the rotarod task was indistinguishable from control litter mates when fed a Se-adequate diet (Fig. 6B). However, feeding $L r p 2^{267 / 267}$ mice a low Se diet for 4 weeks after weaning was sufficient to provoke significant impairments of movement coordination (Fig. 6C). Feeding $\operatorname{Lrp} 2^{267 / 267}$ mice up to ten weeks a low Se diet did not further aggravate the movement phenotype (not shown). We conclude that megalin is involved in uptake of a significant fraction of SePP into the brain, but its lack is less deleterious to cerebral Se metabolism than profound disruption of cerebral selenoprotein expression as in ApoER2-deficient mice. This is consistent with our finding of normal distribution of cortical parvalbumin expressing neurons and lack of astrocytosis (Fig. 6D,E), both phenotypes observed in tRNA ${ }^{\mathrm{Sec}}$-mutant [6;43] and Sepp ${ }^{-/}$mice [39].

\section{Discussion}

The identification of ApoER2 as SePP receptor [23] posed the question whether more lipoprotein-related proteins are able to serve the same function, since they represent a family of structurally related endocytic receptors with sitespecific expression but broad and often overlapping substrate specificities. ApoER2 has been characterized as a coreceptor for reelin and thus is involved in lamination of cerebral and cerebellar cortices [38]. Similarly, during development, megalin mediates the specific uptake of testosterone, in complex with sex hormone-binding globulin, into target tissues [9]. In addition, megalin modulates embryonic forebrain patterning by interference with diffusible 
morphogens, which may be the reason for the midline defect in megalin-deficient mice and patients [14;35]. In the kidney, megalin is involved in the re-uptake of many plasma proteins. For example, lack of megalin in kidney leads to proteinuria, including vitamin D binding protein [20] and transthyretin [34]. Binding of SePP to megalin in overlay assay and association of SePP to wildtype, but not megalin-deficient, embryonic mouse kidney suggested a possible physiologic role of megalin in Se metabolism [22]. Here, we provide further evidence supporting SePP as a physiological megalin cargo in kidney and present data that suggest a further role of megalin in brain Se uptake.

We found evidence that plasma SePP is filtrated in the renal glomerulus and is taken up in a megalin-dependent process along the proximal tubulus. In the absence of functional megalin, some SePP and immunopositive shorter SePP fragments are lost and excreted via the urine to an extent that significantly lowers plasma SePP and Se levels, in particular under conditions of low dietary Se intake as shown in figures 3 and 5. Expression of hepatic selenoproteins, i.e. GPx1, under conditions of megalin- or dietary Se deficiency, parallels circulating SePP levels, suggesting that hepatic SePP secretion is maximal at a given dietary Se intake and is not homeostatically up-regulated in response to urinary loss of SePP. The lack of positive regulation contrasts the negative regulation of hepatic SePP expression during the acute phase response [25].

In spite of little change in renal Se content under the condition of adequate Se diet, megalin-deficiency significantly diminishes renal GPx activity. This finding suggests that the cell type which expresses megalin, the proximal tubule epithelium, contributes most of renal cytosolic GPx activity. Given the significant amount of Se that is lost in megalinmutant mice, Se flux into the kidney tubule is considerable and may exceed the local need for maintaining cellular selenoprotein expression. We hypothesize that this Se is utilized in part for renal de-novo SePP synthesis. This interpretation is consistent with the known expression of Sepp mRNA and protein (this report) in the kidney. Initially, we had interpreted the quantitative lack of circulating SePP in mice unable to express hepatic SePP to argue against a considerable contribution of kidney to circulating SePP concentrations [32]. Considering our new findings, it appears possible that renal SePP synthesis takes place and might contribute to serum SePP concentrations, but is critically dependent on Se derived from hepatic, filtrated SePP. To supply renal tubule cells with a protein though the apical membrane is reminiscent of the recent finding of cathepsin B uptake from the glomerular filtrate and its function there in lysosomal proteolysis [19]. The other secreted selenoprotein derived from the kidney tubulus epithelium is plasma GPx [2]. Accordingly, we find reduced plasma GPx activity in $\operatorname{Lrp} 2^{267 / 267}$ mice, supporting our model of a megalindependent SePP uptake mechanism supplying Se for renal GPx3 biosynthesis: For example, the reduction of GPx3 activity in $\operatorname{Lrp}^{267 / 267}$ mice and Sepp ${ }^{-/}$mice $[31 ; 26]$ is of very similar size and agrees with results from liver-specific $\operatorname{Trsp}^{--}$mice, which are lacking hepatic SePP biosynthesis [32]. Similarly, kidney disease, possibly because of reduced SePP re-uptake, reduces plasma GPx levels [41].

A second major objective of our study was to find out whether megalin is involved in brain SePP uptake. Megalin expression in choroid plexus epithelium is strategically located to extract SePP from blood. Interestingly, choroid plexus also expresses Sepp mRNA [36] and may release newly synthesized SePP into the cerebrospinal fluid [29]. Thus, a similar mechanism as in kidney, involving plasma SePP filtration, uptake, degradation and re-synthesis into another compartment, may be in place in the choroid plexus. Since megalin is also expressed on the apical membrane of ependymal cells lining the ventricles, it would again be equally well located for re-uptake of SePP from cerebrospinal fluid. Such a model is in line with the fact that neuronal expression of the only other known SePP receptor, ApoER2, cannot explain how SePP enters the brain. The severe reduction of brain GPx1 activity in megalinmutant mice, thus emphasizes an unexpected high degree of involvement of megalin in brain Se uptake.

Nevertheless, most neurons, possibly due to preferential SePP uptake via ApoER2, are apparently not Se-deficient, since the neurological phenotype of megalin-mutant mice is mild compared to Sepp $p^{-/}$mice and is unmasked only upon feeding a low Se diet. In contrast, simple dietary Se deficiency does not lead to neurological symptoms. Known phenotypes of mice with reduced cerebral selenoprotein expression are movement impairments, seizures, and astrogliosis, sometimes associated with reduced numbers of cortical parvalbumin interneurons $[6 ; 13 ; 30 ; 31 ; 33 ; 43]$. Megalin-deficient mice only exhibit a moderate impairment of movement coordination when fed a low Se diet. Expression of parvalbumin is normal, astrogliosis not present, and there are no signs of axonal lesions as have been observed in Sepp- mice fed a low Se diet [39;40]. Neuronal ApoER2 expression may thus be sufficient to protect megalin-deficient mice from severe Se loss in functionally important brain structures.

Brain malformations in megalin- and ApoER2-mutant mice seem to be relatively independent of Se metabolism and rather relate to the signalling function of these proteins, since neither Sepp ${ }^{-/-}$nor $A p o E R 2^{-/-}$mice show signs of midline 
defects and Se metabolism is normal in signalling mutants of ApoER2 [18]. However, considering the results presented here, patients suffering from Donnai-Barrow syndrome, like megalin-mutant mice, may be Se deficient in some organs with possible adverse health consequences. Bone metabolic defects in these patients and in megalin-mutant mice are usually attributed to increased urinary vitamin D loss and are treated with supplementary vitamin D [16;20]. Considering the known role of Se and regular expression of selenoproteins in bone metabolism [8], Se supplementation may be a further adjuvant treatment option.

Acknowledgments: The authors thank Anja Fischbach and Vartitér Seher for technical assistance and Dr. Andrew Peterson, San Francisco, USA, for Lrp2 ${ }^{267}$ mice. J.C.-U. was a recipient of a scholarship from the German Academic Exchange Service (DAAD). Further funding was provided by Charité-Universitätsmedizin, Deutsche Forschungsgemeinschaft DFG [Scho849/1-2] to L.S. and U.S. and Mildred Scheel Stiftung Deutsche Krebshilfe to L.S. and J.K..

\section{Footnotes:}

${ }^{1}$ Abbreviations used in this manuscript: ApoER2, apoE receptor 2; GPx, glutathione peroxidase; Lrp2, gene symbol for megalin; $L r p^{267}$, mutant allele of $\operatorname{Lrp} 2$ carrying a stop codon at amino acid 2771; $\operatorname{Lrp} 8$, gene symbol for ApoER2; RAP, receptor-asscoaited protein; SePP, selenoprotein P.

\section{Reference List}

1 Andersen, O. M., Yeung, C. H., Vorum, H., Wellner, M., Andreassen, T. K., Erdmann, B., Mueller, E. C., Herz, J., Otto, A., Cooper, T. G., and Willnow, T. E. (2003) Essential role of the apolipoprotein E receptor-2 in sperm development. J.Biol.Chem. 278, 23989-23995

2 Avissar, N., Ornt, D. B., Yagil, Y., Horowitz, S., Watkins, R. H., Kerl, E. A., Takahashi, K., Palmer, I. S., and Cohen, H. J. (1994) Human kidney proximal tubules are the main source of plasma glutathione peroxidase. Am.J Physiol 266, C367-C375

3 Beffert, U., Nematollah, F. F., Masiulis, I., Hammer, R. E., Yoon, S. O., Giehl, K. M., and Herz, J. (2006) ApoE receptor 2 controls neuronal survival in the adult brain. Curr.Biol. 16, 2446-2452

4 Burk, R. F. and Hill, K. E. (2005) Selenoprotein P: an extracellular protein with unique physical characteristics and a role in selenium homeostasis. Annu.Rev.Nutr. 25, 215-235

5 Burk, R. F., Hill, K. E., Olson, G. E., Weeber, E. J., Motley, A. K., Winfrey, V. P., and Austin, L. M. (2007) Deletion of apolipoprotein E receptor-2 in mice lowers brain selenium and causes severe neurological dysfunction and death when a low-selenium diet is fed. J.Neurosci. 27, 6207-6211

6 Carlson, B. A., Schweizer, U., Perella, C., Shrimali, R. K., Feigenbaum, L., Shen, L., Speransky, S., Floss, T., Jeong, S. J., Watts, J., Hoffmann, V., Combs, G. F., Gladyshev, V. N., and Hatfield, D. L. (2009) The selenocysteine tRNA STAF-binding region is essential for adequate selenocysteine tRNA status, selenoprotein expression and early age survival of mice. Biochem J 418, 61-71

7 Conrad, M. and Schweizer, U. (2010) Unveiling the Molecular Mechanisms Behind Selenium-Related Diseases Through Knockout Mouse Studies. Antioxid.Redox.Signal. 12, 851-865

8 Downey, C. M., Horton, C. R., Carlson, B. A., Parsons, T. E., Hatfield, D. L., Hallgrimsson, B., and Jirik, F. R. (2009) Osteo-chondroprogenitor-specific deletion of the selenocysteine tRNA gene, Trsp, leads to chondronecrosis and abnormal skeletal development: a putative model for Kashin-Beck disease. PLoS.Genet. 5, e1000616 
9 Hammes, A., Andreassen, T. K., Spoelgen, R., Raila, J., Hubner, N., Schulz, H., Metzger, J., Schweigert, F. J., Luppa, P. B., Nykjaer, A., and Willnow, T. E. (2005) Role of endocytosis in cellular uptake of sex steroids. Cell 122, 751-762

10 Hatfield, D. L. and Gladyshev, V. N. (2002) How selenium has altered our understanding of the genetic code. Mol.Cell Biol. 22, 3565-3576

11 Herz, J. and Bock, H. H. (2002) Lipoprotein receptors in the nervous system. Annu.Rev.Biochem 71, 405-434

12 Hill, K. E., Zhou, J., McMahan, W. J., Motley, A. K., Atkins, J. F., Gesteland, R. F., and Burk, R. F. (2003) Deletion of selenoprotein P alters distribution of selenium in the mouse. J.Biol.Chem. 278, 13640-13646

13 Hill, K. E., Zhou, J., McMahan, W. J., Motley, A. K., and Burk, R. F. (2004) Neurological dysfunction occurs in mice with targeted deletion of the selenoprotein $\mathrm{p}$ gene. J.Nutr. 134, 157-161

14 Kantarci, S., Al Gazali, L., Hill, R. S., Donnai, D., Black, G. C., Bieth, E., Chassaing, N., Lacombe, D., Devriendt, K., Teebi, A., Loscertales, M., Robson, C., Liu, T., MacLaughlin, D. T., Noonan, K. M., Russell, M. K., Walsh, C. A., Donahoe, P. K., and Pober, B. R. (2007) Mutations in LRP2, which encodes the multiligand receptor megalin, cause Donnai-Barrow and facio-oculo-acoustico-renal syndromes. Nat.Genet. 39, 957-959

15 Kryukov, G. V., Castellano, S., Novoselov, S. V., Lobanov, A. V., Zehtab, O., Guigo, R., and Gladyshev, V. N. (2003) Characterization of mammalian selenoproteomes. Science 300, 1439-1443

16 Leheste, J. R., Melsen, F., Wellner, M., Jansen, P., Schlichting, U., Renner-Muller, I., Andreassen, T. T., Wolf, E., Bachmann, S., Nykjaer, A., and Willnow, T. E. (2003) Hypocalcemia and osteopathy in mice with kidneyspecific megalin gene defect. FASEB J 17, 247-249

17 Ma, S., Hill, K. E., Caprioli, R. M., and Burk, R. F. (2002) Mass spectrometric characterization of full-length rat selenoprotein $\mathrm{P}$ and three isoforms shortened at the $\mathrm{C}$ terminus. Evidence that three UGA codons in the mRNA open reading frame have alternative functions of specifying selenocysteine insertion or translation termination. J Biol.Chem. 277, 12749-12754

18 Masiulis, I., Quill, T. A., Burk, R. F., and Herz, J. (2009) Differential functions of the Apoer2 intracellular domain in selenium uptake and cell signaling. Biol.Chem. 390, 67-73

19 Nielsen, R., Courtoy, P. J., Jacobsen, C., Dom, G., Lima, W. R., Jadot, M., Willnow, T. E., Devuyst, O., and Christensen, E. I. (2007) Endocytosis provides a major alternative pathway for lysosomal biogenesis in kidney proximal tubular cells. Proc.Natl.Acad.Sci.U.S.A 104, 5407-5412

20 Nykjaer, A., Dragun, D., Walther, D., Vorum, H., Jacobsen, C., Herz, J., Melsen, F., Christensen, E. I., and Willnow, T. E. (1999) An endocytic pathway essential for renal uptake and activation of the steroid 25-(OH) vitamin D3. Cell 96, 507-515

21 Nykjaer, A. and Willnow, T. E. (2002) The low-density lipoprotein receptor gene family: a cellular Swiss army knife? Trends Cell Biol. 12, 273-280

22 Olson, G. E., Winfrey, V. P., Hill, K. E., and Burk, R. F. (2008) Megalin mediates selenoprotein P uptake by kidney proximal tubule epithelial cells. J Biol.Chem. 283, 6854-6860

23 Olson, G. E., Winfrey, V. P., Nagdas, S. K., Hill, K. E., and Burk, R. F. (2007) Apolipoprotein E receptor-2 (ApoER2) mediates selenium uptake from selenoprotein $P$ by the mouse testis. J.Biol.Chem. 282, 12290-12297

24 Rayman, M. P. (2000) The importance of selenium to human health. Lancet 356, 233-241 
25 Renko, K., Hofmann, P. J., Stoedter, M., Hollenbach, B., Behrends, T., Köhrle, J., Schweizer, U., and Schomburg, L. (2009) Down-regulation of the hepatic selenoprotein biosynthesis machinery impairs selenium metabolism during the acute phase response in mice. FASEB J 23, 1758-1765

26 Renko, K., Werner, M., Renner-Müller, I., Cooper, T. G., Yeung, C. H., Hollenbach, B., Scharpf, M., Köhrle, J., Schomburg, L., and Schweizer, U. (2008) Hepatic selenoprotein P (SePP) expression restores selenium transport and prevents infertility and motor-incoordination in Sepp-knockout mice. Biochem J 409, 741-749

27 Riese, C., Michaelis, M., Mentrup, B., Gotz, F., Kohrle, J., Schweizer, U., and Schomburg, L. (2006) Seleniumdependent pre- and posttranscriptional mechanisms are responsible for sexual dimorphic expression of selenoproteins in murine tissues. Endocrinology

28 Saito, Y., Sato, N., Hirashima, M., Takebe, G., Nagasawa, S., and Takahashi, K. (2004) Domain structure of bifunctional Selenoprotein P. Biochem.J. Pt,

29 Scharpf, M., Schweizer, U., Arzberger, T., Roggendorf, W., Schomburg, L., and Köhrle, J. (2007) Neuronal and ependymal expression of selenoprotein P in the human brain. J.Neural Transm. 114, 877-884

30 Schomburg, L., Schweizer, U., Holtmann, B., Flohé, L., Sendtner, M., and Köhrle, J. (2003) Gene disruption discloses role of selenoprotein P in selenium delivery to target tissues. Biochem.J. 370, 397-402

31 Schweizer, U., Michaelis, M., Köhrle, J., and Schomburg, L. (2004) Efficient selenium transfer from mother to offspring in selenoprotein-P-deficient mice enables dose-dependent rescue of phenotypes associated with selenium deficiency. Biochem.J. 378, 21-26

32 Schweizer, U., Streckfuss, F., Pelt, P., Carlson, B. A., Hatfield, D. L., Köhrle, J., and Schomburg, L. (2005) Hepatically derived selenoprotein $\mathrm{P}$ is a key factor for kidney but not for brain selenium supply. Biochem.J. 386, $221-226$

33 Seiler, A., Schneider, M., Förster, H., Roth, S., Wirth, E. K., Culmsee, C., Plesnila, N., Kremmer, E., Radmark, O., Wurst, W., Bornkamm, G. W., Schweizer, U., and Conrad, M. (2008) Glutathione peroxidase 4 senses and translates oxidative stress into 12/15-lipoxygenase dependent- and AIF-mediated cell death. Cell Metab 8, 237248

34 Sousa, M. M., Norden, A. G., Jacobsen, C., Willnow, T. E., Christensen, E. I., Thakker, R. V., Verroust, P. J., Moestrup, S. K., and Saraiva, M. J. (2000) Evidence for the role of megalin in renal uptake of transthyretin. J Biol.Chem. 275, 38176-38181

35 Spoelgen, R., Hammes, A., Anzenberger, U., Zechner, D., Andersen, O. M., Jerchow, B., and Willnow, T. E. (2005) LRP2/megalin is required for patterning of the ventral telencephalon. Development 132, 405-414

36 Steinert, P., Bachner, D., and Flohé, L. (1998) Analysis of the mouse selenoprotein P gene. Biol.Chem. 379, 683691

37 Stosnach, H. (2005) Trace element analysis using a benchtop TXRF-spectrometer. Powder Diffraction 20, 141145

38 Trommsdorff, M., Gotthardt, M., Hiesberger, T., Shelton, J., Stockinger, W., Nimpf, J., Hammer, R. E., Richardson, J. A., and Herz, J. (1999) Reeler/Disabled-like disruption of neuronal migration in knockout mice lacking the VLDL receptor and ApoE receptor 2. Cell 97, 689-701 
39 Valentine, W. M., Abel, T. W., Hill, K. E., Austin, L. M., and Burk, R. F. (2008) Neurodegeneration in mice resulting from loss of functional selenoprotein $\mathrm{P}$ or its receptor apolipoprotein E receptor 2 . $\mathrm{J}$

Neuropathol.Exp.Neurol. 67, 68-77

40 Valentine, W. M., Hill, K. E., Austin, L. M., Valentine, H. L., Goldowitz, D., and Burk, R. F. (2005) Brainstem axonal degeneration in mice with deletion of selenoprotein $\mathrm{p}$. Toxicol.Pathol. 33, 570-576

41 Whitin, J. C., Tham, D. M., Bhamre, S., Ornt, D. B., Scandling, J. D., Tune, B. M., Salvatierra, O., Avissar, N., and Cohen, H. J. (1998) Plasma glutathione peroxidase and its relationship to renal proximal tubule function. Mol.Genet.Metab 65, 238-245

42 Willnow, T. E., Hilpert, J., Armstrong, S. A., Rohlmann, A., Hammer, R. E., Burns, D. K., and Herz, J. (1996) Defective forebrain development in mice lacking gp330/megalin. Proc.Natl.Acad.Sci.U.S.A 93, 8460-8464

43 Wirth, E. K., Conrad, M., Winterer, J., Wozny, C., Carlson, B. A., Roth, S., Schmitz, D., Bornkamm, G. W., Coppola, V., Tessarollo, L., Schomburg, L., Köhrle, J., Hatfield, D. L., and Schweizer, U. (2010) Neuronal selenoprotein expression is required for interneuron development and prevents seizures and neurodegeneration. FASEB J 24, 844-852

44 Zarbalis, K., May, S. R., Shen, Y., Ekker, M., Rubenstein, J. L., and Peterson, A. S. (2004) A focused and efficient genetic screening strategy in the mouse: identification of mutations that disrupt cortical development. PLoS.Biol. 2, E219

45 Zheng, G., Bachinsky, D. R., Stamenkovic, I., Strickland, D. K., Brown, D., Andres, G., and McCluskey, R. T. (1994) Organ distribution in rats of two members of the low-density lipoprotein receptor gene family, gp330 and LRP/alpha 2MR, and the receptor-associated protein (RAP). J Histochem.Cytochem. 42, 531-542 
Table 1:

Tissue Se content in $L r p 2^{267 / 267}$ mice

Diet

Lrp2

Kidney

$\mathrm{ng} / \mathrm{mg} \pm \mathrm{SEM}$

Cerebral cortex

$\mathrm{ng} / \mathrm{mg} \pm \mathrm{SEM}$

Liver

$\mathrm{ng} / \mathrm{mg} \pm \mathrm{SEM}$
RDA Se

$0.15 \mathrm{mg} \mathrm{Se} / \mathrm{kg}$

$$
2.06 \pm 0.39 \quad 1.80 \pm 0.35
$$

$267 / 267$
$.80 \pm 0.35$

$0.89 \pm 0.24 \quad 0.63 \pm 0.17$

$0.87 \pm 0.23$

Low Se

$0.08 \mathrm{mg} \mathrm{Se} / \mathrm{kg}$

$+/+\quad 267 / 267$

$1.66 \pm 0.38 \quad 0.66 \pm 0.16 *$

$2735 \pm 588 \quad 1573 \pm 582$

$504 \pm 105^{\#}$

$0.66 \pm 0.14$

$497 \pm 196^{\#}$

Number of animals per diet $\mathrm{n}=3$ for kidney and liver (only males), $\mathrm{n}=6$ for cortex. $\mathrm{SEM}=$ standard error of the mean, * significant at the $5 \%$ level vs. respective $+/+;{ }^{\#}$ significant vs. corresponding RDA group. Student's t-test. 


\section{Figure legends:}

Figure 1: In vitro-SePP binding to megalin-expressing BN16 cells. (A) HepG2 cells were metabolically labelled with ${ }^{75} \mathrm{Se}$-selenite. $20 \mu 1$ and $10 \mu 1$ of concentrated ${ }^{75} \mathrm{Se}$ labelled culture medium was applied to a polyacrylamide gel and co-migrated with mature SePP as determined by SePP immunoblotting. (B) Dose-dependent binding of ${ }^{75} \mathrm{Se}-\mathrm{SePP}$ to BN16 cells. Normalized to maximum binding. (C) ${ }^{75} \mathrm{Se}-\mathrm{SePP}$ binding to BN16 cells is RAP-sensitive. Pre- and coincubation with $0.1 \mathrm{mg} / \mathrm{ml}$ recombinant soluble GST-RAP significantly reduced ${ }^{75} \mathrm{Se}$-SePP-binding to BN16 cells. Cells were incubated with $72 \mathrm{ng} / \mathrm{ml} \mathrm{SePP}$, a concentration close to the $50 \%$ binding concentration. Binding of $75 \mathrm{Se}-$ SePP in absence of RAP was set to $100 \%$. All experiments were repeated at least twice with independent ${ }^{75} \mathrm{Se}-\mathrm{SePP}$ preparations.

Figure 2: Urinary SePP and Se excretion in megalin-mutant mice. (A) Structure of the mutant megalin allele, $\operatorname{Lrp}^{267}$, of line 267. A missense mutation in the extracellular domain Y2721X likely disrupts endocytic function. (B) Proteinuria in $\operatorname{Lrp}^{267 / 267}$ mice. Coomassie-stained polyacrylamide gel. (C) Increased urinary Se excretion in $\operatorname{Lrp} 2^{267 / 267}$ mice fed a Se adequate diet (RDA) containing $0.15 \mathrm{ppm} \mathrm{Se}\left(\mathrm{n}=4-6 ;{ }^{*} \mathrm{p}<0.05\right.$, Student's t-test). (D) SePP is detected in urine from homozygous megalin-mutant mice, but not wild-type controls. Urinary SePP levels are decreased in mice fed low Se diet $(0.08 \mathrm{ppm} \mathrm{Se})$. (E) Enzymatic deglycosylation (+PNGase) reveals the heterogeneity of SePP polypeptides. (F) Immunohistochemical localization of megalin (red) and SePP-immunopositive vesicles (green) in the proximal tubule. No SePP-staining in megalin-deficient cells. SePP-uptake correlates with megalin expression on the single cell level in a conditional megalin-mutant mouse (ApoE-Cre; Lrp $\left.2^{f l i f t}\right)$, which shows mosaic inactivation. $(\mathrm{G})$ The diagram illustrates that SePP uptake is more pronounced in the most proximal part of the convoluted segment, while megalin expression extends further.

Figure 3: Blood Se parameters are reduced in $\mathbf{L r p 2}^{\mathbf{2 6 7 / 2 6 7}}$ mice. Mice were fed either Se-sufficient (RDA) or low Se diets for 4 weeks after weaning. (A) Serum Se content is reduced in $\operatorname{Lrp} 2^{267 / 267}$ mice fed Se-sufficient diet. Animals fed Se-deficient diet displayed reduced serum Se concentrations and this deficiency was aggravated further by megalininsufficiency. (B) Western Blot against mouse SePP in serum and densitometric evaluation. Serum $(0.2 \mu 1)$ from three animals per group was applied to a reducing polyacrylamide gel. (C) Plasma GPx activity is reduced in $\operatorname{Lrp} 2^{267 / 267}$ mice. However, GPx activity is less strongly affected by genotype and diet than serum Se content. n=4-6 per genotype. $* * \mathrm{p}<0.01$ Student's t-test vs. wild-type RDA control. $\# \mathrm{p}<0.05$ vs.corresponding wild-type.

Figure 4: Expression of selenoproteins in kidney is diminished in megalin-mutant mice. (A) Immunoblot for GPx1. Wildtype liver served as positive control (pos.) and liver from a liver-specific Trsp ${ }^{-/-}$mouse as negative control (neg.). A representative blot of two experiments with identical results is shown. For each genotype and diet, two animals are analyzed. $\beta$-actin served as loading control. (B) Renal cytosolic GPx activity was measured in 4-6 animals per genotype and diet. ANOVA followed by Bonferroni's post-hoc test. ${ }^{*} \mathrm{p}<0.05,{ }^{* *} \mathrm{p}<0.01,{ }^{* * *} \mathrm{p}<0.001$. (C) Immunohistochemistry for GPx1 (green) and megalin (red). (D) The diagram illustrates that GPx1 immunoreactivity (green) is strongest in the most proximal part of the convoluted segment coinciding with SePP uptake (Fig. 2F). (E) Immunoblot for SePP. Multiple SePP bands are detected in kidney, including the $38 \mathrm{kDa}$ band corresponding to fulllength, non-glycosylated SePP (circle). The renal SePP isoform distribution is different from serum. A Sepp ${ }^{-/}$negative control (neg.) supports the identity of SePP-immunoreactive bands. Glycosylated SePP species are indicated by a bar. (F) For densitometric quantification of the immunoblot shown in (E) 4 individual male mice per genotype and diet were evaulated. Partially glycosylated SePP isoforms are more sensitive to limited Se supply than the 38kDa nonglycosylated species. $\beta$-actin was used for normalization.

Figure 5: Se status in liver and testis. (A) Immunoblot analysis of hepatic GPx1 expression as marker of hepatic selenoprotein biosynthesis. (B) Activity of hepatic GPx1 is a more sensitive marker of hepatic Se content than Western Blot and reveals reduced GPx1 activity in megalin-deficient mice fed the RDA diet. n=3-4 male animals per genotype. ${ }^{*} \mathrm{p}<0.05, * * * \mathrm{p}<0.001$ ANOVA with Bonferroni's post-hoc test. n.s. $=$ non significant. (C) Testicular GPx4 is an established marker for testis Se status and male fertility. $\operatorname{Lrp} 8^{-/}$testis is shown for comparison, since Lrp8 is the SePP receptor in testis. $\beta$-actin served as loading control. Densitometric evaluation of GPx4 expressed relative to wild-type on RDA diet. 
Figure 6: Brain phenotype of megalin-deficient mice. (A) Cerebral cytosolic GPx activity is reduced in $\operatorname{Lrp} 2^{267 / 267}$ mice fed Se adequate (RDA) diet. (B) Motor coordination of $\operatorname{Lrp} 2^{267 / 267}$ mice as assessed by rotarod analysis is only reduced when mice are fed a low Se diet for 4 weeks after weaning. (C) No astrogliosis as assessed by glial fibrillary acidic protein (GFAP) immunoreactivity in the primary somatosensory cortex (barrel field) of $L r p 2^{267 / 267}$ mice fed Se adequate diet. (D) Normal number and distribution of parvalbumin expressing cortical interneurons. Scale bars $200 \mu \mathrm{m}$. 
Figure 1 A

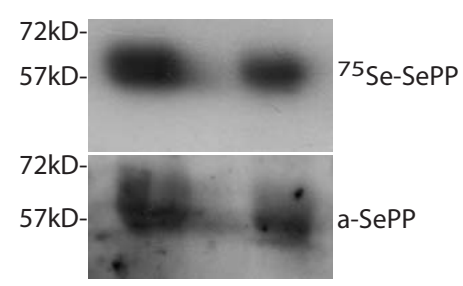

B SePP binding to BN16 cells

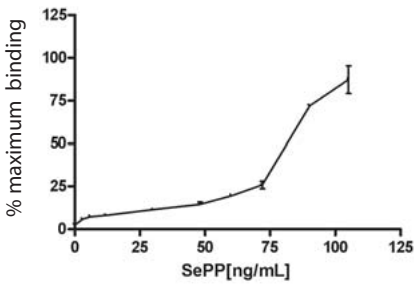

C

RAP competition

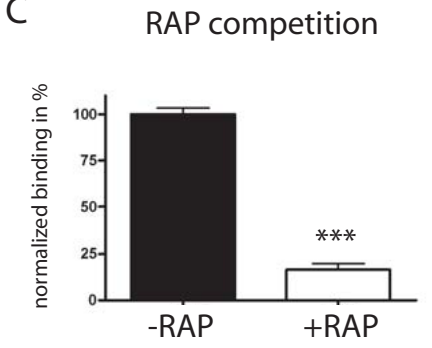

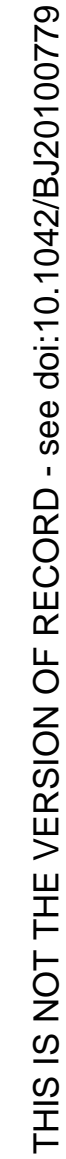


Figure 2

A

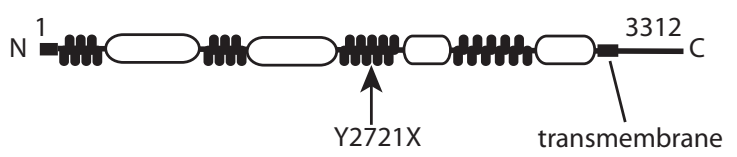

B

C

urinary Se excretion
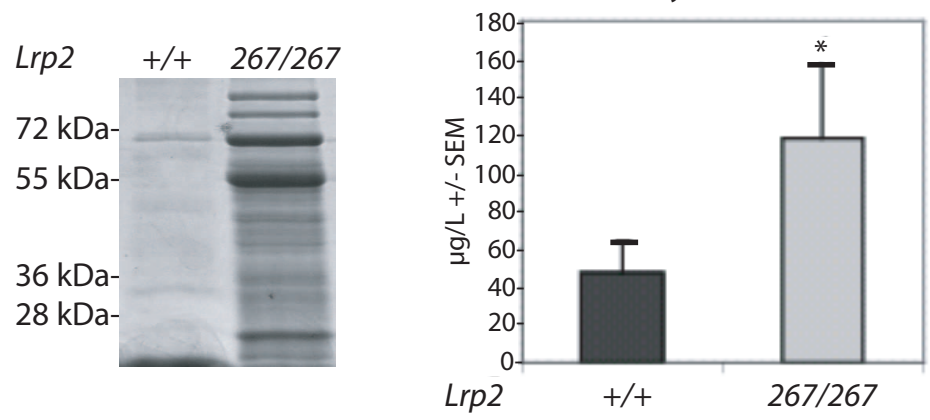

$\mathrm{D}$

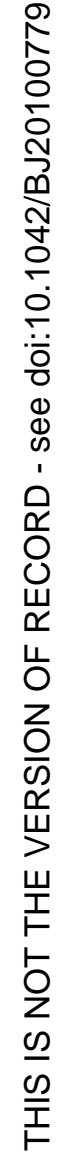
\begin{tabular}{lcc|cccc}
\multicolumn{2}{c}{ urine } & \multicolumn{2}{c}{ serum } & serum & urine \\
Lrp2 & $+/+$ & $267 / 267$ & $+/+$ & $267 / 267$ & $+/+$ & $267 / 267$
\end{tabular} food Se low RDA low RDA Iow RDA low RDA

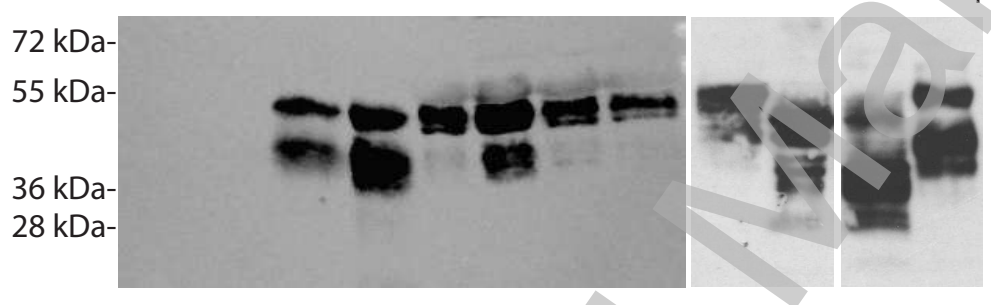

F

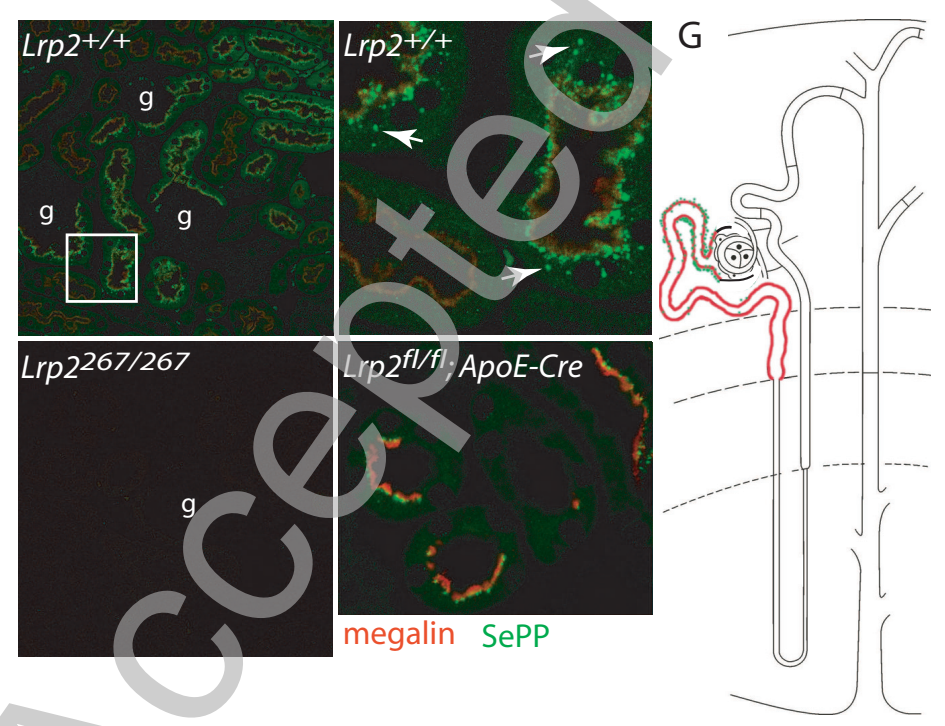

Licenced copy. Copying is not permitted, except with prior permission and as allowed by law. (C) 2010 The Authors Journal compilation (c) 2010 Portland Press Limited 
Figure 3

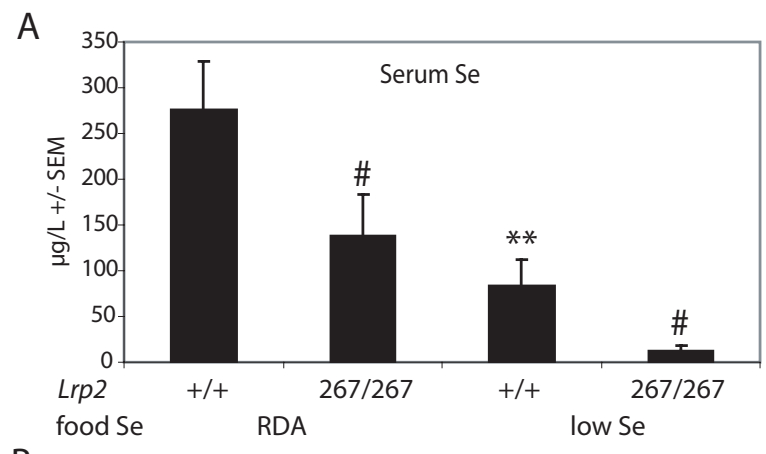

B
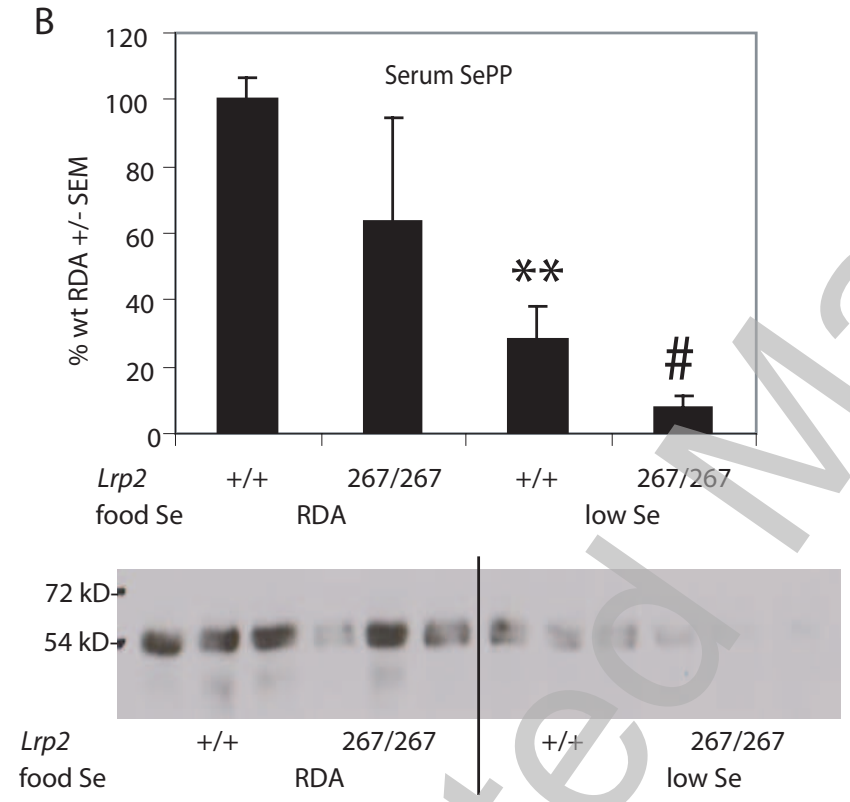

C

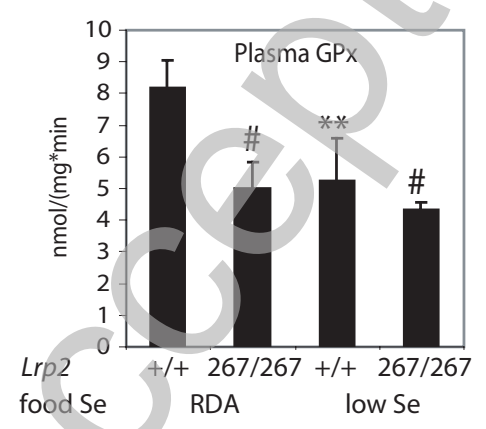


Figure 4

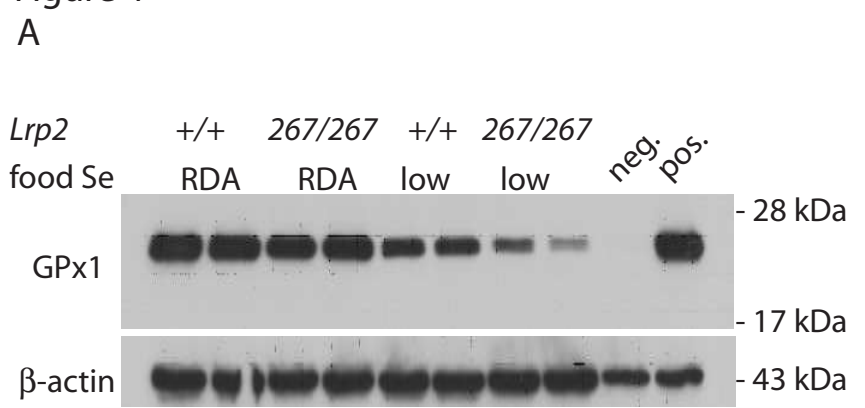

C
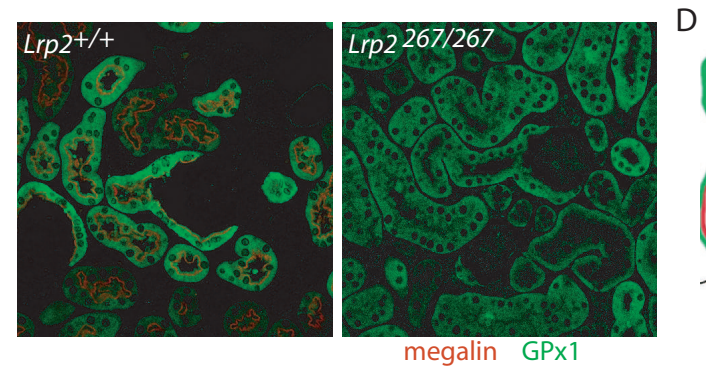

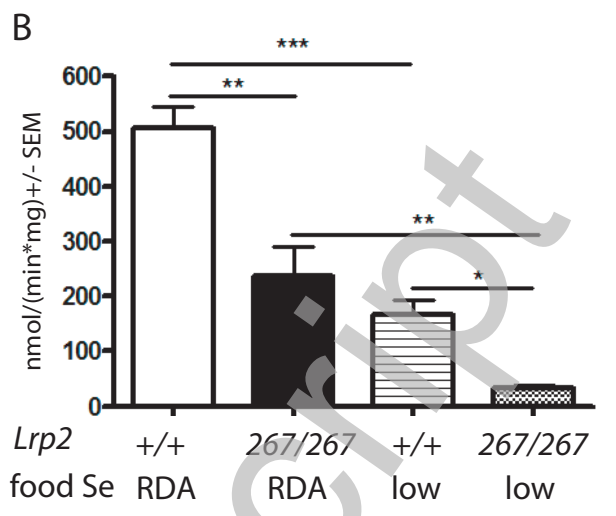

E

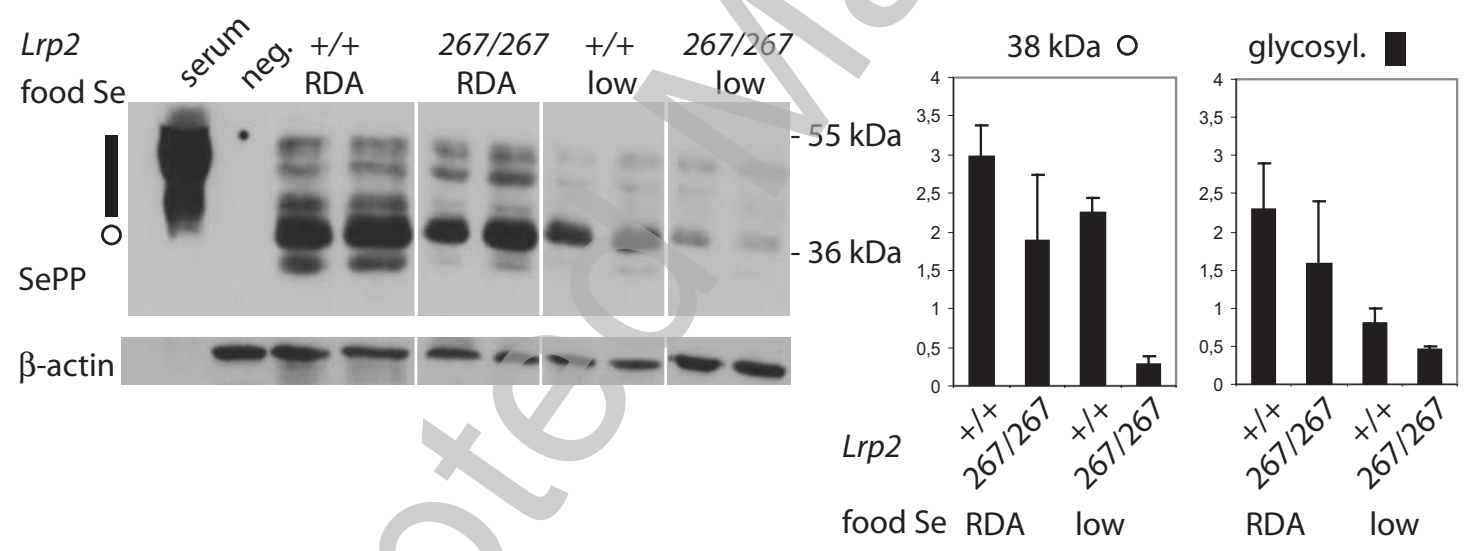

Licenced copy. Copying is not permitted, except with prior permission and as allowed by law. (C) 2010 The Authors Journal compilation (c) 2010 Portland Press Limited 
Figure 5

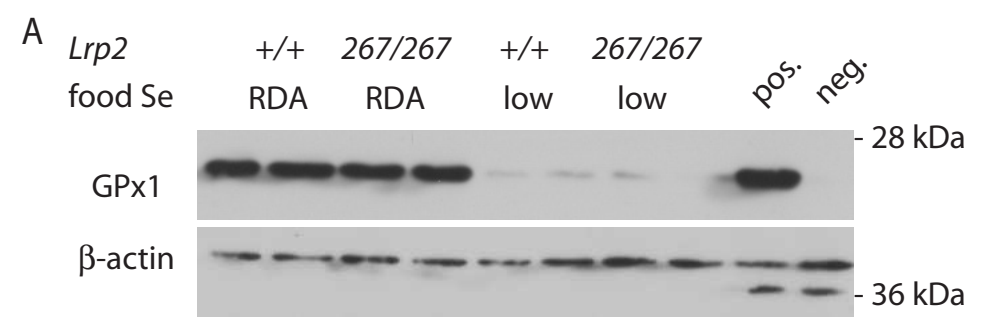

B

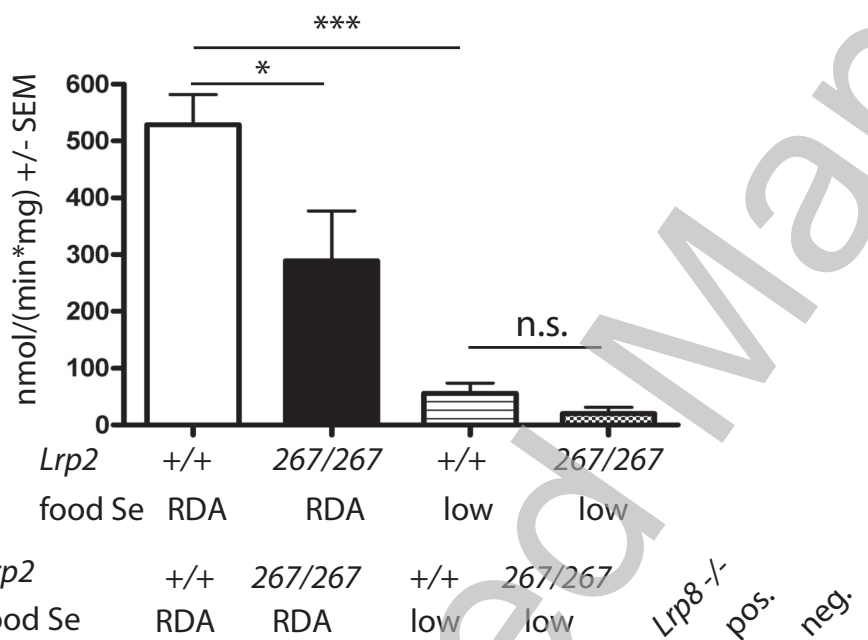

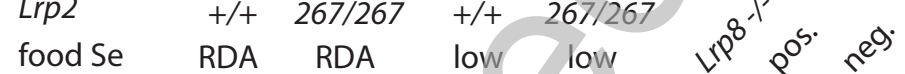

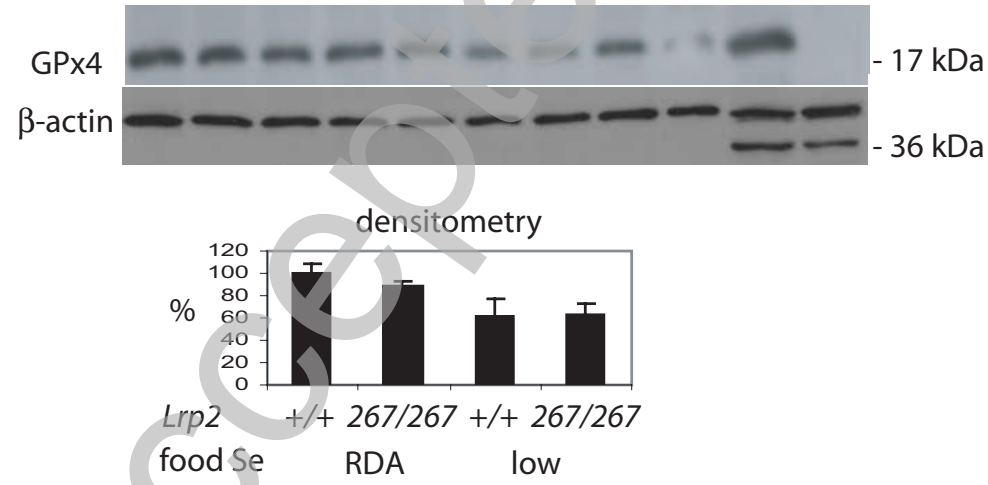


Figure 6

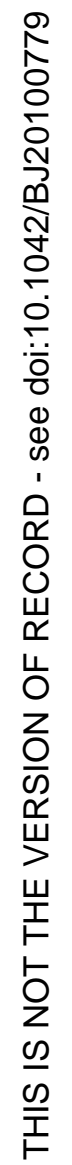

A

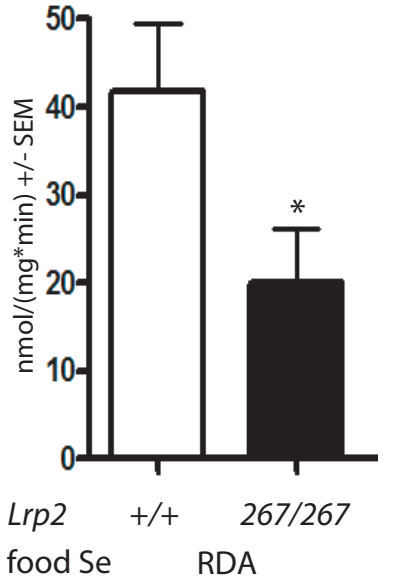

$\mathrm{D}$

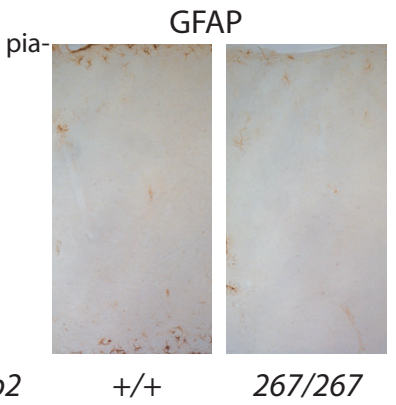

B

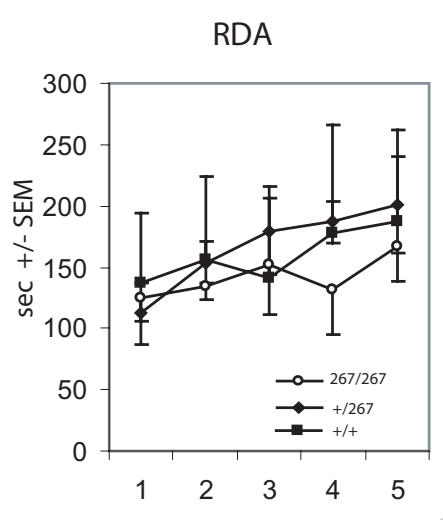

E parvalbumin

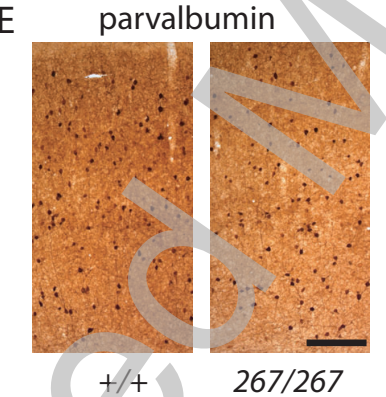

C low Se

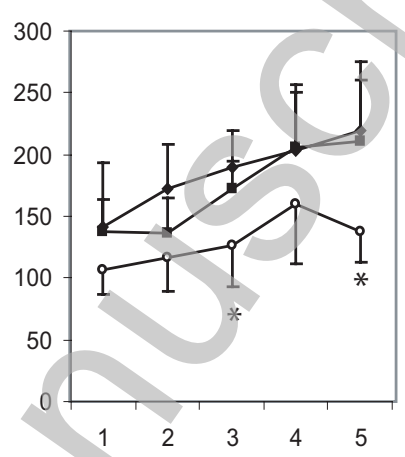

